\title{
LENDO ODISSEIA DE HOMERO (SEGUNDO JOÃO VÍTOR), DE GUSTAVO PIQUEIRA: UMA ANÁLISE LITERÁRIA
}

READING THE ODYSSEY OF HOMER (ACCORDING TO JOÃO VÍTOR), BY GUSTAVO PIQUEIRA: A LITERARY ANALYSIS

\section{Vanessa Rita de Jesus Cruz ${ }^{1}$}

Resumo: Esse texto tem como objetivo realizar uma breve análise da obra Odisseia de Homero (segundo João Vítor), de Gustavo Piqueira, publicada em 2013. Para tanto, abordaremos algumas questões referentes à Literatura e o seu ensino, à formação do leitor e à Semiótica, que "se trata de uma das teorias voltadas para a investigação a respeito do modo como os sujeitos produzem sentidos para os textos e, portanto, tem implicações para uma didática da leitura" (SILVA, 2017, p. 196). Ressaltamos, também, o papel essencial que o professor desempenha no processo de aproximar o leitor do texto literário.

Palavras-chave: ensino de Literatura; formação de leitores; leitura literária na escola.

Abstract: This text aims to make a brief analysis of Gustavo Piqueira's Odyssey of Homer (according to João Vítor), published in 2013. For this, we will address some issues related to Literature and its teaching, the formation of the reader and Semiotics, which "is one of the theories for the investigation of the way in which the subjects produce meanings for the texts and, therefore, has implications for a didactics of reading." (SILVA, 2017, 196). We emphasize, also, the essential role that the teacher plays in the process of approach the reader from the literary text.

Keywords: teaching of Literature; training of readers; literary reading in school.

\section{Introdução}

Ao longo do tempo, a Literatura foi recebendo conceitos e funções distintas e, a partir daí, diferentes graus de importância. Sabemos que ela não é o único meio de proporcionar deleite e conhecimento, mas se apresenta como um caminho possível, por isso mesmo, tanto se tem debatido sobre o seu espaço nos currículos escolares, na escola, na sala de aula, em casa e nas rodas de amigos.

Órgãos diversos têm se dedicado às propagandas de incentivo à leitura, oferta gratuita de livros e projetos de leitura. Todos são "convocados" a incentivar e colaborar para que crianças e adolescentes entrem em contato com os livros literários e mantenham com eles um

\footnotetext{
${ }^{1}$ Doutoranda pelo Programa de Pós-Graduação em Letras: Ensino de Língua e Literatura da Universidade Federal do Tocantins. Professora da Rede Estadual do Tocantins. vanessalinguagens@ hotmail.com
} 
vínculo produtivo, satisfatório e - poderíamos até dizer -, de dependência e prazer. Sendo assim, os mais variados meios e materiais são utilizados para atender a esse fim, tais como a leitura dos clássicos ou de obras adaptadas, a leitura compartilhada ou solitária, a utilização do livro impresso ou digital, o espaço da sala de aula ou da biblioteca, dentre outros.

A seguir, teceremos alguns comentários sobre o ensino de Literatura, a leitura literária e a teoria semiótica, para que possam subsidiar nossa análise sobre a referida obra e nos auxiliem a pensar algumas questões sobre o papel do professor e da escola enquanto mediadores de leitura.

\section{Considerações teóricas e analíticas}

Acreditamos que a leitura do texto literário, como uma prática social, pode permitir ao leitor ir além da simples leitura (COSSON, 2011), ou seja, é capaz de possibilitar a emancipação, a autonomia, a reflexão e a humanização do leitor. Ela pode, ainda, provocar a fruição e a sensibilidade, auxiliar a formação efetiva de leitores críticos.

Conforme pontua Teresa Colomer, por muitos séculos a Literatura teve como papel principal ser o "eixo vertebral do ensino linguístico, a formação moral, a consciência de uma cultura com raízes clássicas greco-latinas e, desde o século XIX, de aglutinadora de cada nacionalidade" (COLOMER, 2007, p. 15). O que não significa, necessariamente, que, mesmo com tantas funções, "os alunos tenham se dedicado a ler obras literárias nas aulas, nem que a literatura lida fosse adequada à sua capacidade e interesse" (COLOMER, 2007, p. 15). Ainda segundo a autora, em meados do século XIX, em alguns países começou-se a escrever livros que foram pensados para a etapa escolar, mas a instrução moral continuava a ser a função principal desses livros, que traziam relatos edificantes, histórias humorísticas, pequenas peripécias emocionantes, poemas ou fragmentos, patrimônios da literatura nacional. Alguns desses livros mantiveram as sequências narrativas com um tom educativo a partir de um protagonista infantil. Em outros países, os livros de leitura coletiva tinham a forma de "novelas escolares", se tratavam de narrativas extensas e coesas, que traziam o conhecimento do passado, ou se referiam ao espaço geográfico ou ainda representavam um livro de unidade patriótica. Essas novelas escolares, que eram lidas nas classes finais do curso primário, segundo Colomer, representavam "uma garantia de que qualquer pessoa teria lido ao menos um livro recreativo 
completo em sua vida e se tornavam um vínculo de referência coletiva" (COLOMER, 2007, p. 17).

No que diz respeito à etapa secundária, o modelo de ensino de Literatura que perdurou por muito tempo foi o que propiciava a criação de discursos orais e escritos, por meio do eixo da retórica, baseando-se na leitura de autores gregos e latinos; buscava-se "agrupar as referências culturais, estudar os recursos expressivos utilizados nessas obras e tomar as citações de autoridade ou os exemplos adequados para incluí-los na construção do próprio discurso" (COLOMER, 2007, p. 17), modelo que foi substituído, a partir do século XIX, por um que visava o estudo da história da literatura, por meio de "uma linha de evolução cronológica literária" (COLOMER, 2007, p 17), a partir de textos em que os alunos procuravam comprovar as características que tinham estudado. Tanto no primeiro modelo quanto no segundo, realizavase uma leitura - orientada pelo professor - de fragmentos de obras.

Dessa forma, podemos dizer que, por muito tempo, os livros que se tinham presentes nas aulas eram as obras chamadas escolares juntamente com as antologias de textos de autores conhecidos: "tratava-se de 'belas páginas' para moldar o gosto e imitar nos exercícios de redação; poemas e fragmentos para memorizar e compartilhar como referências da coletividade cultural ou nacional; e fábulas e contos morais curtos para educar em relação a valores e comportamentos" (COLOMER, 2007, p. 17). Sendo assim, é possível concluirmos que a leitura literária não se mostrava como esperado nas atividades escolares dos alunos.

Mesmo diante dessa situação, poderíamos dizer que, segundo Colomer (2007), há um discurso escolar que pensa a necessidade de a escola permitir que os alunos tenham acesso à biblioteca com livros adequados para a sua idade. Esse discurso já existe há mais de um século e vários programas de leitura, que conclamam a participação de todos, têm se disseminado em diferentes países, governos, secretarias de educação, ONGs, para falar e pensar a leitura literária.

"Como, então, recriar e fomentar, no espaço do aprendizado escolar, o entusiasmo pela leitura de livros fazendo com que o encontro com eles se torne um evento fascinante e sedutor e afete o leitor em suas sensibilidades máximas?" (OLINTO, 2009, p. 157). Sabemos que a escola representa, hoje, o espaço privilegiado - embora não exclusivo - para o contato entre o leitor e os textos literários. Sendo assim, o professor possui um papel crucial nesse processo: 
além de desenvolver nos alunos a competência comunicativa e a sensibilidade para o texto literário, também é intermediador.

Essa intermediação do professor, que é essencial para que os alunos compreendam a obra, só é possível, evidentemente, se ele tiver o embasamento e o conhecimento necessários para desenvolver o seu trabalho, além de autonomia para poder realizá-lo.

É primordial proporcionar espaço e tempo para que os estudantes possam compartilhar com os colegas e com o professor os pontos de vista e as impressões sobre a obra, possam ver e sentir a Literatura e o contato com as obras como uma necessidade. A escola também é responsável pela crescente familiarização do aluno com o texto literário.

Falar da Literatura e da leitura escolar requer que pensemos a relação leitor-texto, que, na escola, se dá de maneira diferente daquela apregoada por algumas teorias literárias - a leitura como um ato individual, gratuito e solitário. É preciso considerar que um mesmo texto pode despertar diferentes leituras por parte de um mesmo leitor, assim como diferentes leitores podem apresentar leituras divergentes a partir de um mesmo texto. A leitura - ou leituras - que se faz de um texto depende, também, da relação criada, desenvolvida e aperfeiçoada entre este e o seu leitor.

Diante das breves considerações feitas sobre a Literatura e o seu ensino, sobre a leitura literária e sobre a escola enquanto espaço que propicia a leitura, passemos agora à análise da obra já mencionada. A obra Odisseia de Homero (segundo João Vítor), do escritor e designer Gustavo Piqueira, publicada pela editora Gaivota, em 2013, traz uma história que é narrada pelo garoto João Vítor, aluno do sexto ano, que não é esperto nem honesto. João Vítor, diante da iminência de reprovar de ano, por ter faltado à prova final, tem como última possibilidade de ser aprovado, realizar um resumo e interpretação de uma versão adaptada - uma Odisseia de 47 páginas, com ilustrações coloridas - da obra Odisseia, de Homero, mas ele se engana e acaba pegando na biblioteca a versão original do épico.

Ele até justificou para a professora que faltou à aula por motivo de problemas de saúde na família, mas seus pais desmentiram a sua história, o que fez com que ele se sentisse injustiçado:

Mas, professora Denise, quem pode afirmar que disseram a verdade? Por que todo mundo acreditou na versão deles e não na minha? Absurdo, professora! Absurdo! Além do mais, quem garante que meus pais conhecem minha família inteira? Quem? Ninguém! Posso, por exemplo, ser filho adotivo sem que nenhum deles saiba. Ou ter um irmão distante, do qual eles nunca ouviram falar. Ou ainda um quinto avô, além 
dos dois por parte de pai e dos outros dois por parte de mãe. Por que não? São todas hipóteses perfeitamente possíveis (PIQUEIRA, 2013, p. 11).

João Vítor tinha hábito da leitura das versões da internet, que, segundo ele, "São melhores. Curtinhos, resumidos. Vão direto ao ponto, sem enrolação" (PIQUEIRA, 2013, p. 14), quando havia a necessidade de fazer algum trabalho escolar. Dessa vez foi diferente, pois deixou para fazer o trabalho no último dia e à noite, não podendo mais usar a internet; só pode acessá-la até as nove, e já passava das dez e meia da noite. Ele não poderia pedir aos pais para abrirem uma exceção, pois tinha dito à mãe que já havia realizado a leitura do livro. Não restou alternativa: teve que ler a obra que havia pegado na biblioteca da escola, o clássico de quatrocentas páginas. Só descobre depois de meia-noite, quando liga para seu colega Fumaça, que não havia pegado a versão resumida, própria para a sua idade, como os outros colegas.

Versão adaptada? No meu não. Apenas Odisseia de Homero. O seu diz Odisseia de
Homero, versão adaptada? Deve ser por isso? Deve ser por isso o quê, Fumaça? O
motivo da diferença? O que significa versão adaptada? Sei lá também! Não faz
sentido, Fumaça! Não podem existir duas Odisseias tão diferentes assim! Não faz
nenhum sentido! Um livro é um livro! Um filme é um filme, uma pessoa é uma pessoa,
um carro é um carro! Alguns vêm com vidro elétrico, outros sem. Mas o modelo é o
mesmo. A diferença não pularia de quarenta e sete para mais de trezentas páginas.
Não Fumaça! Não estou dizendo que minha edição da Odisseia tem vidro elétrico!
Livros não têm vidro, Fumaça! (...) A diferença entre meu livro e o seu é como a que
existe entre um Fiat Uno e um caminhão. Não faz sentido ambos se chamarem
Odisseia de Homero da Silva. Tá bom! Sem da Silva, que seja! Odisseia de Homero.
Não faz sentido! (...) só me resta a versão "caminhão" da Odisseia (PIQUEIRA, 2013,
p. 48-49).

À medida que João Vítor nos conta a história clássica, realizando um resumo de cada canto - no total de 24 -, mistura fatos do seu mundo familiar e também de novelas que assiste, tornando a história um tanto engraçada. Cada capítulo é o resumo do livro Odisseia e aos fatos que parecem originais, ele vai acrescentado interferências de forma crítica, inteligente e até mesmo sarcástica, conforme o entendimento que possui das situações lidas, mas em alguns casos acaba confundindo elementos da história ao relacioná-los com fatos de seu cotidiano, deturpando completamente o sentido conforme o que seria uma leitura legitimada.

No meio da narração de seu trabalho, João Vítor vai deixando vários recados para a sua professora Denise, pontuando o seu esforço em incrementar o livro original e corrigir os "erros" e as "burrices" cometidas pelo autor Homero da Silva. 
Que livro malfeito! Impressionante! Está escrito que Telêmaco viaja de carro, mas um carro puxado por cavalos. Todo mundo, todo mundo mesmo, sabe que um carro é puxado por pneus, não por cavalos. Cavalos puxam charretes. Corrigi a burrice do autor. Telêmaco vai de charrete a Esparta (PIQUEIRA, 2013, p. 33).

Eles não usam a palavra "camarada" no livro professora. Mas quis incrementar. A Odisseia precisa de uma incrementada, concorda? Ah, se todos os seus alunos fossem como eu, não é verdade? Analiso brilhantemente um livro e ainda melhoro o que está ruim! Tenho a certeza de que o sonho da senhora é entrar numa sala da aula e dar de cara com trinta João Vítor, sentados em suas cadeiras. Quietos, atentos. Realizando trabalhos consistentes, incrementando livros medíocres (PIQUEIRA, 2013, p. 69).

$\mathrm{Na}$ visão dele, encontra erros absurdos na história de Homero e concerta-os. Ele não faz ideia de quem seja Homero: "Homero da Silva não é um bom escritor, professora. Desculpe se ele for seu parente ou amigo" (PIQUEIRA, 2013, p. 21); muitas narrações no livro são para ele incoerentes e absurdas: "Professora, professora... Se há um herói nessa história toda, sou eu. Eu mesmo, João Vítor, por aguentar tantos absurdos" (PIQUEIRA, 2013, p. 25). Até mesmo o nome do autor ele "incrementa":

Professora, na edição que peguei da biblioteca não havia sobrenome do autor, apenas o primeiro nome, Homero. Como todo mundo tem sobrenome, coloquei um bem comum. Um chute, confesso. Se errei, quero apenas deixar claro: a culpa não foi minha, mas sim da biblioteca do colégio que empresta livros incompletos a seus alunos, pouco se lixando se alguém repetir de ano por cauda disso" (PIQUEIRA, 2013, p. 7).

João Vítor acredita que Odisseia é um plágio de uma novela que ele assistiu. Em toda a narração vai associando a história com o mundo dele. Segundo ele, o livro começa mal, pois há um deus chamado Poseidon, e Deus só tem um e o nome dele é Deus mesmo, o seu filho não se chama Ciclope Polifemo e sim Jesus, que foi crucificado e não cegado; associa Hermes a um motoboy; chama Penélope de "mutreteira" porque tece a mortalha para o sogro durante o dia e desmancha à noite para não ter que escolher um novo marido; critica Telêmaco, filho de Ulisses, o tempo todo, o acha um molengão, sem atitude, "peso morto", "mimado playboy", "palerma", "pamonha", "inútil”, que vê Antínoo criticar a sua mãe e não faz nada: "Antínoo fala, em público, que a mãe do rapaz não é honesta. Sabe o que isso significa, certo? Aqui no bairro, que ela é... Bom, a senhora sabe o que significa, professora. Então. Qual a reação de Telêmaco? Nenhuma, professora. Nenhuma. Se é com a minha mãe, parto pra cima e arrebento. Na hora" (PIQUEIRA, 2013, p. 23). Não faz distinção entre as coisas, acredita que Policasta, após dá banho em Telêmaco passa azeite em seu corpo, "Azeite! Aquilo que nós, pessoas normais, usamos para temperar salada" (PIQUEIRA, 2013, p. 32). Na visão de João Vítor, Ulisses, além de ser um galinha, é um bandido: 
(...) Ou seja: bandido. Não há outra palavra para definir Ulisses a não ser essa, professora Denise. Ladrão, assassino e sequestrador? Bandido. E o pior, conta seus crimes tranquilão: "chacinei homens, levei suas mulheres". Como pode, professora? É muita impunidade, não? Muita. Meus pais vivem comentando sobre isso aqui em casa. Dizem que os ricos cometem as maiores barbaridades e sempre se safam. Que moramos no país do colarinho branco. Pelo visto, Ulisses também tinha costas quentes. Do contrário, não arriscaria tagarelar por aí sobre suas falcatruas (PIQUEIRA, 2013, p. 62).

É importante ressaltarmos que as partes em que João Vítor expressa a sua opinião ou se dirige à professora possuem uma fonte diferente das partes em que se retrata o resumo da obra Odisseia.

Além da escrita humorística, Piqueira insere ilustrações que mesclam a montagem de fotos atuais - imagens pensadas por João Vítor - com gravuras neoclássicas do século XVIII referentes à Odisseia. As ilustrações são outro elemento que chama a atenção no livro. Elas são muito importantes para a compreensão do texto, são divertidas e evidenciam a visão de João Vítor sobre a história.

De modo geral, poderíamos dizer que, desde a capa, que retrata uma síntese do livro, a obra já nos convida para a leitura. Na primeira parte, João Vítor faz o resumo dos cantos da obra, ao mesmo tempo em que, informalmente, dialoga com a professora, questiona os comportamentos das personagens da obra de Homero e relaciona-as com pessoas de sua vida. Na segunda parte, “Odisseia de João Vítor (segundo Gustavo Piqueira)”, o autor fala sobre as leituras que realizou de Odisseia, tratando de questões sobre tradução e obras adaptadas. Na terceira parte, que é apresentada em um papel diferente, "Odisseia de Homero através dos séculos", Piqueira nos apresenta ilustrações que retratam diferentes episódios da Odisseia, mostrando como as personagens tiveram as feições e as roupas adaptadas a cada século. $\mathrm{Na}$ última parte, temos uma "Breve enciclopédia da Odisseia (sem João Vítor para atrapalhar)", com esclarecimentos sobre o autor, a obra e os personagens da Odisseia, de Homero.

Segundo o autor, João Vítor tanto é um princípio de avacalhação das coisas quanto um princípio da necessidade de valorização da nossa relação pessoal com a arte, o quanto nos envolvemos e o modo como nos envolvemos. Ainda segundo o autor, "o livro não é um manifesto contra essas adaptações, mas ele é uma tiração de sarro com elas, sim” (PIQUEIRA, 2014. Trecho de entrevista para o programa Livros em Revista da TV Geração Z).

João Vítor acaba criando uma versão, que é apresentada com senso de humor, mas que se constitui como uma forma de analisarmos e apreendermos a realidade que nos cerca, uma 
vez que provoca questionamentos, traz vários elementos da obra para a sua realidade e, mais, proporciona-nos a reflexão sobre o ensino e a leitura literária.

De posse do resumo da obra, acreditamos serem relevantes algumas questões ${ }^{2}$ - não temos a pretensão de responder a todas no momento, mas pretendemos, ao menos, abrir espaço para a reflexão - a saber: O que pode e o que não pode o leitor? O que o leitor lê? Ele, leitor, lê tudo do mesmo jeito? Quem define o que é ideal? Como o sujeito reage diante do objeto livro? É importante/necessário forçar a leitura dos clássicos? A leitura dos clássicos pode atrapalhar a leitura por prazer? O gosto pode surgir a partir da leitura por obrigação? A obra tem relação com a realidade do sujeito aluno/leitor? Uma versão adaptada se adequa ao currículo escolar?

Na obra descrita, temos um tipo de leitor. Aquele que ainda não usufrui do prazer da leitura, lê, quando necessário, e resumos da internet. A relação do sujeito com o livro e a leitura se dá por diferentes intencionalidades e demandas. João Vítor vai ao texto com uma intenção bem definida: realizar trabalhos escolares.

Conforme os regimes de interação propostos pela Semiótica (MELO; SILVA, 2015, recorrendo a Landowski, 2002), poderíamos dizer que o leitor pragmático que a escola ajuda a formar pode ser um leitor programado: um leitor que, embora passando por diferentes textos, não consegue, de fato, se entregar a nenhum deles, mesmo que faça todos os exercícios propostos e siga as orientações daqueles que já leram as mesmas obras; aqui teríamos o regime da programação. Esse leitor pode, ainda, buscar no texto apenas aquilo que possibilita que ele alcance uma finalidade: identificar um gênero, uma classe de palavra, uma corrente literária, lendo apenas fragmentos que possibilitem que ele encontre o que tanto procura; teríamos o regime da manipulação. Outro leitor, mesmo que se preocupe em saber tipologia ou gênero, pode encontrar, em outro momento, prazer na leitura literária, sendo o livro e a leitura literária como "parceiro na interação"; trata-se do regime de ajustamento. Por fim, teríamos o tipo de leitor que procura/encontra a obra para viver emoções e não para cumprir exigências, tais como identificar gênero, classe de palavra ou ter que depois produzir um texto. O texto pode chegar a esse leitor por diferentes meios, indicado por diferentes sujeitos. Teríamos o regime do assentimento. É importante ressaltar que "não somos leitores qualificados por uma única

\footnotetext{
${ }^{2}$ Algumas dessas questões são baseadas no artigo O que pode o leitor?, de Luiza Helena da Silva e Márcio Araújo de Melo, Revista Entreletras, Araguaína/TO, v.6, n.2, jul/dez. 2015.
} 
tipologia, não nos manifestamos da mesma forma diante de todos os objetos, o prazer não se localiza nos mesmos pontos" (MELO; SILVA, 2015, p. 131).

Sabemos que a ideia de valor, de cânone e de crítica literária se apresenta como critérios para que se eleja e se leia um livro (MELO, 2015). Sendo assim, não é de surpreender que Odisseia, de Homero, tenha sido solicitada para leitura em uma turma de sexto ano, embora uma versão adaptada. Transforma-se a obra em fragmentos, por meio de cortes, e alguém decide o que é essencial para o leitor, criando histórias de amor e de heróis para entreter, mas que nem sempre permite que o leitor estabeleça o tipo de relação que pretende ter com a história:

\begin{abstract}
Quando você lê um livro a graça toda é a relação que você tem com aquele livro (...) e cada um entra de um jeito porque aí cada um vê alguma coisa que bate com a sua vida, com coisa que $c \hat{e}$ gosta, coisa que $c \hat{e}$ não gosta, coisa que te incomoda, coisa que te diverte, mas é uma relação pessoal. Quando você começa a cortar, você tá decidindo o tipo de relação que o leitor vai ter com aquela história (...) Como se você falasse assim olha eu quero que você pegue isso aqui (...) vai por esse caminho; então você limita as possibilidades, que é claro, a criança de dez anos ou enfim quando uma criança em idade escolar que tá lendo a Odisseia integral nunca vai pegar esse caminho, não importa né, o que importa é que você à priori direciona, fala oh desse livro aqui eu quero que você entenda isso aqui, tá? Cê conclui o livro e perde um pouco da graça (...). (PIQUEIRA, 2014. Trecho de entrevista para o programa Livros em Revista da TV Geração Z).
\end{abstract}

Não é a nossa intenção, nesse trabalho, discorrer sobre as adaptações, mas vale dizer que nem sempre as mesmas trazem a "essência" da história original, algumas têm a intenção de se tornar uma história "fácil", com heróis e fatos amorosos e lendo-as estaríamos de fato lendo um clássico? Há mesmo a necessidade de lê-lo? Nas adaptações, outra pessoa decide quais aspectos de uma obra merecem ser lembrados e quais merecem ser "jogados" no esquecimento e, com isso, alguma coisa o leitor perdeu.

A prática da leitura requer constantes reflexões. Pelo resumo da obra, é nítida a confusão que o sujeito/aluno João Vítor faz em relação aos sentidos da obra original. Não se pode contestar a importância de Homero para a Literatura. Sua epopeia foi padrão estético e ético por toda a Grécia, mas a Odisseia não proporcionou prazer estético algum em João Vítor. É evidente que ele não tem um percurso de leitor, leu por uma obrigação - fazer um trabalho de recuperação -, não houve um acompanhamento da docente ou dos pais e talvez, ainda, não fosse uma leitura indicada para o seu perfil de leitor, seu desconhecimento histórico interfere na leitura, mas, por outro lado, proporciona modos de ler "estranhos" ao padrão. 
Para a leitura de certos autores e obras não se faz necessária a intermediação do professor e de um conhecimento mais elaborado sobre a Literatura. Em contrapartida, há autores em que essa intermediação e aprofundamento de saberes literários se fazem necessários. $\mathrm{Na}$ escola, muitas vezes, o texto literário tem sido convocado para subsidiar questões referentes ao gênero, à tipologia textual ou à necessidade de que o aluno produza um novo texto. A produção de sentido que aquele texto pode proporcionar fica em segundo plano ou nem aparece. A Literatura, muitas vezes, é explorada apenas em seus aspectos técnicos, o aluno não chega a gozar do texto. É o que acontece com o nosso personagem leitor.

João Vítor leu. Algum sentido atribuiu ao que leu, mas, provavelmente, não o esperado pela professora e nem gozou do prazer que uma leitura pode proporcionar. O sujeito é o mesmo após a leitura de um livro? Ao que parece, João Vítor não acrescentará a sua vida a possibilidade de construção de novos sentidos - a não ser aquele que tanto deseja, ser aprovado. Uma nova leitura, realizada em determinado percurso e, se houver a necessidade, com a devida intermediação, nos torna capazes de produzir novos sentidos, uma vez que na interação com o outro também somos transformados e convidados a atribuir novas significações.

O gosto, segundo Fiorin (1997 apud SILVA 2017, p. 202), "não é um dom natural como quer a ideologia, mas um acontecimento social". O sujeito aluno precisa ser munido de competências que o auxiliem na construção da formação desse gosto e faça com que ele esteja atento à organização textual e aos procedimentos que ele pode acionar ao realizar a leitura. Considerando que o sentido não está dado nos textos, mas depende daquele que o lê, podemos dizer que não interessa apenas o texto, mas também o sujeito e a própria vida, conforme demonstra Eric Landowski, recorrendo a Greimas:

Contudo, em Greimas, a motivação inicial da reflexão foi uma interrogação sobre o sentido em geral. No começo, não se tratava somente de se perguntar sobre a significação dos textos, mas sim do "sentido das atividades humanas", do "sentido da história", ou, simplesmente, segundo uma expressão familiar, do "sentido da vida". (LANDOWSKI, 2012, p. 129) ${ }^{3}$

Atribuir sentido é um posicionamento inerente ao ser humano, que seja apenas relacionando com suas experiências cotidianas, que seja acionando competências construídas no seu percurso de leitor com a intermediação do professor. Nesse sentido, a semiótica

\footnotetext{
${ }^{3}$ No original: No obstante, en Greimas, también el resorte inicial de la reflexión fue una interrogación acerca del sentido en general. En él, al comienzo, no se trataba solamente de preguntarse sobre la significación de los textos, sino del "sentido de las actividades humanas", del "sentido de la historia", o simplesmente, según una expresión que le era familiar, del "sentido de la vida".
} 
interessa-se pelo texto, mas interessa-se também pelos processos que o sujeito convoca ao realizar a leitura.

\section{Considerações finais}

Ler e dar sentido ao mundo. Para subsidiar essas breves - e temporárias - considerações finais, recorremos a uma citação dos professores e pesquisadores Luiza Helena Oliveira da Silva e Márcio Araújo de Melo:

Há o que ler nos livros, nas cartilhas, mas também nos muros e nas lições apreendidas na relação com outros sujeitos. Ler é então verbo transitivo que pressupõe distintos objetos, a demandar diferentes saberes para um sujeito em constante aprendizado, o que nos remete ao conceito de letramento (MELO; SILVA, 2015, p. 124).

Desse modo, o ato e a possibilidade de ler se apresentam a nós por meio de diferentes formas, vindos de diferentes lugares e podem se dar a partir de diferentes finalidades. Nem todos são tocados da mesma forma e, portanto, os sentidos podem se diferenciar e provocar sensações distintas. Alguns serão seduzidos, outros "virarão as costas" para o texto, pois o leitor “(...) possui certo direito de validar o texto literário, bem como de avaliar sua capacidade de convencimento"; existe um "leitor avaliador, que tem o poder de dizer não ao texto, de não ser seduzido por ele" e "uma leitura que se coloca num lugar oscilante de certeza, pois nem sempre convence, nem sempre seduz todos os leitores” (MELO, 2015, p. 171).

Acreditamos que a Literatura continuará a formar crianças e jovens leitores, seja na leitura solitária, seja na leitura partilhada no ambiente escolar, para uma consciência autônoma, crítica e ativa.

\section{Referências}

COLOMER, Teresa. Andar entre livros - A leitura literária na escola. Tradução de Laura Sandroni. São Paulo: Global, 2007.

COSSON, Rildo. Letramento literário: teoria e prática. São Paulo: Contexto, 2011.

CRUZ, Vanessa Rita de Jesus. Ensino de literatura infantil e juvenil e diversidade sexual: perspectivas e desafios para a formação de leitores na contemporaneidade. 163f. Dissertação (Mestrado em Ensino de Língua e Literatura). Universidade Federal do Tocantins, Araguaína, 2011. 
LANDOWSKI, Eric. ?Habría que rehacer la semiótica? Contratexto. n. 20, p. 127-155, 2012.

MELO, Márcio Araújo de. Entre livros, leitores e realidade. Via Atlântica. n. 28, p. 161-176, dezembro, 2015.

MELO, Márcio Araújo de; SILVA, Luiza Helena Oliveira da. O que pode o leitor? Entreletras. v. 6, n. 2, p. 120-132, jul/dez., 2015.

OLINTO, Heidrun Krieger. A economia das emoções na crítica e teoria da literatura. In: OLINTO, Heidrun Krieger; SCHOLLHMMER, Karl Erik (Organizadores). Literatura e crítica. Rio de Janeiro: 7Letras, 2009. p. 148-165.

PIQUEIRA, Gustavo. Odisseia de Homero (segundo João Vítor). São Paulo: Gaivota, 2013.

PIQUEIRA, Gustavo. Trecho de entrevista (setembro de 2014). Entrevistador: Ralph Peter. Programa Livros em Revista da TV Geração Z, 2014. Disponível em: <www.gustavopiqueira.com.br/odisseia.html>. Acesso em: 01de julho de 2018.

SILVA, Luiza Helena Oliveira da. Não vejo o mundo com seus olhos: inquietações sobre a leitura e literatura na perspectiva da semiótica didática. In: BRITO, Áustria Rodrigues; SILVA, Luiza Helena Oliveira da; SOARES, Eliane Pereira Machado (Organizadoras). Divulgando conhecimentos de linguagem: pesquisas em língua e literatura no ensino fundamental. Rio Branco: Nepan Editora, 2017. p. 195-2011. 